\title{
PROCEDIMENTO OPERACIONAL PADRÃO COMO BASE FORTALECEDORA PARA A ASSISTÊNCIA INTEGRAL EM UMA UNIDADE PSIQUIÁTRICA ${ }^{1}$
}

\author{
STANDARD OPERATING PROCEDURE AS A STRENGTHENING BASIS FOR \\ COMPREHENSIVE CARE IN A PBDCHHttAT/RळCorgXIIT.48195/jie2021-176
}

\author{
Heloisa Catto Dal Forno ${ }^{2}$, Adriana Dall Asta Pereira ${ }^{3}$, Carla Lizandra de Lima \\ Ferreira $^{4}$,Caroline Colares da Rosa ${ }^{5}$
}

\section{RESUMO}

Objetivou-se com este trabalho relatar o manejo da contenção mecânica por meio de uma assistência integral e humanizada, e a importância dos POP's (Procedimento Operacional Padrão) de instituições de Saúde em unidades psiquiátricas. O presente estudo trata-se de um relato de experiência, de abordagem qualitativa, realizado na disciplina de Estágio II, do curso de Enfermagem, durante o segundo semestre de 2018, no período de quatorze de agosto a cinco de outubro do mesmo ano, na unidade psiquiátrica de um hospital de grande porte caracterizado como um hospital geral, de ensino, público e 100\% SUS localizado na Região Central, no município de Santa Maria, no RS- Brasil. A partir da vivência sobre a qual se relata e reflete torna-se importante destacar que a saúde mental como um todo deve ser mais reconhecida, estudada e entendida como fator essencial a cada ser humano.

Palavras-chave: Assistência Integral à Saúde, Enfermagem, Psiquiatria.

\section{ABSTRACT}

The objective of this work was to report the management of mechanical restraint by means of a comprehensive and humanized assistance, and the importance of POPs (Standard Operating Procedure) of Health institutions in psychiatric units. This study is an experience report, with a qualitative approach, carried out in the Stage II discipline of the Nursing course, during the second semester of 2018, from the fourteenth of August to the fifth of October of the same year, in psychiatric unit of a large hospital characterized as a general, teaching, public and 100\% SUS hospital located in the Central Region, in the municipality of Santa Maria, in $R S$-Brazil. From the experience about which it is reported and reflected, it is important to highlight that mental health as a whole should be more recognized, studied and understood as an essential factor for each human being.

Keywords: Comprehensive Health Care, Nursing, Psychiatry.

\footnotetext{
${ }^{1}$ Trabalho de Iniciação Científica

${ }^{2}$ Enfermeira -. E-mail: helo.c.dalforno@gmail.com

${ }^{3}$ Colaboradora. Docente do curso de Enfermagem - Universidade Franciscana. E-mail: adrianadallastapereira @ gmail.com

${ }^{4}$ Orientadora. Docente do curso de Enfermagem- Universidade Franciscana. E-mail: carlalizandralferreira@ gmail.com

${ }^{5}$ Orientadora. Estudante do $10^{\circ}$ semestre do curso de Enfermagem- Universidade Franciscana. E-mail:

rosa.caroline@ufn.edu.br
} 


\section{INTRODUÇÃO}

A assistência psiquiátrica, por muitos anos esteve atrelada a tratamentos restritos tendo como foco a doença. Conversar com o paciente, permitir-se como profissional demostrar carinho e realizar uma assistência pautada na cientificidade e olhar consciente não era objetivo nas primeiras instituições psiquiátricas existentes no Brasil, as quais deveriam apenas omitir os sintomas psíquicos (SOUZA, 2018).

Vigiar, controlar e punir era três ações de responsabilidade da Enfermagem nos manicômios sendo elas as mais tristes e violentas que um indivíduo poderia se submeter (GUIMARÂES et al.,2013). Sobretudo, as inúmeras práticas violentas ausência de estímulos e interação com familiares e amigos impossibilitavam que os indivíduos voltassem a ter um convívio social saudável.

Atualmente, ainda são empregadas práticas terapêuticas, como a contenção mecânica, que visam controlar os pacientes confusos, desorientados, com risco a si mesmo e aos outros indivíduos (SOUZA, 2018). Para isso, os profissionais devem se fortalecer e garantir por meio de leis e resoluções o melhor cuidado ao realizar a contenção mecânica, a fim de, evitar consequências ou agravar o quadro clínico e psíquico dos pacientes.

Torna-se imprescindível considerar que novos modelos de atenção à saúde mental no Brasil vêm sendo aplicados para garantir a integralidade do cuidado e proteção das pessoas portadoras de transtornos mentais, conforme estabelecido pela lei 10.216, de 6 de abril de 2001 (BRASIL, 2001).

Sendo assim, práticas como a contenção mecânica são realizadas com faixas de tecido sob uma técnica supervisionada e realizada por profissionais de Enfermagem aonde não se venha a ter complicações como lesão por pressão, pneumonia, trombose venosa profunda e ainda prejuízo a habilidades cognitivas (SOUZA, 2018).

Torna-se relevante, conforme estabelecido pela Resolução do Cofen n ${ }^{\circ} 427 / 2012$, dentre todas as suas argumentações, evidenciar em seu Art. $1^{\circ}$ a supervisão do profissional enfermeiro ao ser realizada a contenção mecânica, exceto em situação de urgência e emergência, e ainda estabelece que esta prática, preferencialmente, esteja de acordo com protocolos estabelecidos pelas instituições de saúde (COFEN, 2012).

É de responsabilidade de o profissional Enfermeiro habilitar-se sobre as condutas a serem realizadas com os pacientes e, sobretudo é de grande importância que o profissional saiba conduzir, planejar e aperfeiçoar junto a sua equipe protocolos e planos terapêuticos baseados em legislações e na cientificidade para que se consiga alcançar a excelência na assistência à saúde em casos de manejos que necessitem contenção mecânica. Também é importante que o profissional atue respeitando o cuidado integral e humanizado nos diferentes procedimentos realizados (BRASIL, 2009).

Dessa forma, a reflexão sob o tema contenção mecânica ainda é muito restrita, além do entendimento sobre os cuidados a serem realizados durante este manejo. Surge a partir da vivência a necessidade de relatar o manejo e a importância dos POP's (Procedimento Operacional Padrão) de instituições de Saúde em unidades psiquiátricas.

\section{METODOLOGIA}

O presente estudo trata-se de um relato de experiência, de abordagem qualitativa, realizado na disciplina de Estágio II, do curso de Enfermagem, durante o segundo semestre de 2018, no período de quatorze de agosto a cinco de outubro do mesmo ano, na unidade psiquiátrica de um hospital de grande porte caracterizado como um hospital geral, de ensino, público e $100 \%$ SUS localizado na Região Central, no município de Santa Maria, no RS- Brasil. 
A pesquisa qualitativa está apresentada no estudo dos significados, valores, atitudes e percepções, que correspondem à realidade social, isso porque cada ser humano pensa, interpretam e concluem de maneiras diferentes as questões do cotidiano (MINAYO, 2009).

No local de prática são realizadas atividades da rotina de Enfermagem, bem como atividades multiprofissionais realizadas pelos residentes que atuam na unidade. Realizam-se atividades de confraternização com os familiares o que favorece o vínculo entre profissional, paciente e família.

A equipe atuante na unidade é composta por nove Enfermeiros e dezoito técnicos de Enfermagem, além de Auxiliares de Enfermagem. A unidade conta com 30 leitos, sendo duas enfermarias femininas, duas masculinas e dois quartos individuais ou apartamentos que podem ter até dois leitos cada.

Durante o período de realização do estágio, percebeu-se a necessidade de relatar à importância do POP destinado a atenção psicossocial já existente na unidade psiquiátrica, o qual se destina a técnica da contenção mecânica e sua realização de forma humanizada. Nesse sentido foram realizados encontros nos três turnos com a equipe de enfermagem, onde foram revistas as técnicas de contenção do paciente internado na unidade.

\section{RESULTADOS E DISCUSSÃO}

A presença de Procedimentos Operacionais Padrão em instituições hospitalares, e em conformidade com a vivência realizada em uma unidade Psiquiátrica, os POPs possibilitam a padronização de procedimentos, criação de normas e rotinas bem como garantem o uso de metodologias adequadas para a assistência (BARBOSA et al. 2011).

O mesmo autor destaca ainda, que a elaboração dos POPs, de maneira com que o trabalho multiprofissional esteja incluído, possibilita a uniformidade e organização do serviço. Assim, entende-se por POPs, o detalhamento descrito para o alcance da uniformidade em funções específicas.

Este relato de experiência busca fortalecer a importância dos Procedimentos Operacionais Padrão em unidades psiquiátricas, a fim de uniformizar, e baseados em fundamentos científicos promover a qualidade dos processos assistências, possibilitando o aperfeiçoamento contínuo (FLORES et al. 2011). Também se torna importante relatar o manejo da contenção mecânica baseado no protocolo já existente na unidade psiquiátrica de vivência acadêmica, visto que para a qualidade do cuidado deve se haver boas práticas e atitudes profissionais (MARQUES, 2012).

Na psiquiatria onde aconteceu a vivência acadêmica, a contenção mecânica é usada para limitar o comportamento agressivo, muitas vezes em surto psicótico, para evitar danos a sí próprio e aos outros. Por vez vista como um procedimento que agride a integridade dos pacientes, pois os colocam amarrados ao leito, mas esta intervenção mesmo impactando em alguns casos é indispensável quando outras medidas não apresentam efeitos (FLORES et al. 2011).

Os trabalhos multiprofissionais e interdisciplinares dentro da unidade psiquiátrica possibilitam e engrandecem as relações interpessoais entre os profissionais, família e usuário. Para isso este trabalho em equipe deve considerar e reconhecer cada vez mais o perfil profissional e as responsabilidades dos envolvidos precisa-se compartilhar as informações, discutir os procedimentos e condutas visando reorganizar os problemas de maneira ética reflexiva (BARROSO et al. 2018).

O POP já existente na unidade psiquiátrica encontra-se no Manual de Gerenciamento da Rotina do hospital, junto à unidade de atenção psicossocial. Sua estrutura conta com o objetivo do procedimento, responsabilidade, aplicação, procedimento, resultados e ação corretiva. 
Os materiais usados neste procedimento são faixas próprias para a contenção mecânica, para a segurança dos profissionais envolvidos e responsáveis para realizar o procedimento é descrito luvas de procedimento. Quanto aos cuidados especiais destacam-se a contenção da região torácica somente quando necessário, observar a segurança e conforto do paciente, avaliar frequentemente o aspecto das extremidades dos membros superiores e inferiores (presença de cianose e edema), em crianças conter somente membros superiores, evitar uso de ataduras de crepe ou lençóis, avaliar a necessidade de solicitar auxílio ou orientação à equipe de Enfermagem da psiquiatria, solicitar sempre a prescrição médica deste cuidado (HUSM, 2016).

O mesmo autor descreve para a realização do procedimento técnico os seguintes passos: higienizar as mãos, reunir o material e levá-lo até o leito, orientar o paciente sobre o que está sendo realizado e o motivo, conter os punhos e tornozelos com faixas resistentes, sem laços, amarrar as faixas nas laterais do leito, fixando de maneira que não deslize, conter braços e coxas, se necessário, manter o paciente em posição confortável, anotar no prontuário.

Como resultados são assegurados os cuidados necessários para realizar a imobilização do paciente no leito, facilitando a assistência de Enfermagem e segurança do paciente. Ainda, como ação corretiva entendida como a avaliação durante o período em que o paciente fica contido descreve-se a avaliação da intervenção frequentemente, revendo a necessidade da continuidade do procedimento junto com toda a equipe de enfermagem e médicos (SOUZA, 2018; HUSM, 2016).

Dessa forma, é evidente a importância de POP's em unidades psiquiátricas, pois garantem a padronização de técnicas de enfermagem, qualidade assistencial e padronização das atividades realizadas. Ainda, a descrição dos POP's deve conter, em cada um de seus passos, uma prévia avaliação crítica e sequencial a fim de minimizar os erros e buscar transformações culturais nas instituições e unidades psiquiátricas no âmbito prático, teórico e reflexivo (ROCHA, 2014).

\section{CONSIDERAÇÕES FINAIS}

Por meio deste relato buscou-se contribuir para a visibilidade do manejo da contenção mecânica por meio de uma assistência integral e humanizada, bem como a importância de protocolos relativos à mesma em instituições de saúde.

Conclui-se ao término do estágio curricular unidade psiquiátrica, que a saúde mental como um todo deve ser mais reconhecida, estudada e entendida como fator essencial a cada ser humano. 


\section{REFERÊNCIAS}

BARBOSA, C. M; ZULIANI, M. F. M; SALVADOR, A. B. C; MANGIONE, J. A. A importância dos procedimentos operacionais padrão (POPs) para os centros de pesquisa clínica. Rev Assoc Med Bras. v. 57, n. 2, pág. 134-135, 2011.

BARROSO, C. O. N; RODRIGUES, E. M; HANZELMANN, R. S; CARVALHO, C. M. S. M; MARTINS, J. S. A; SANTOS, L. F. M. A inserção do enfermeiro na equipe multiprofissional do centro de atenção psicossocial. Revista Científica Multidisciplinar das Faculdades São José- Ciência Atual. Rio de Janeiro. v. 11, nº 1, pág. 02-14. 2018.

BRASIL. LEI No 10.216, DE 6 DE ABRIL DE 2001. Presidência da República, Casa Civil, Subchefia para Assuntos Jurídicos. 2001.

BRASIL. Ministério da Saúde (BR). Secretaria de Gestão do Trabalho e da Educação na Saúde. Departamento de Gestão da Educação em Saúde. Política Nacional de Educação Permanente em Saúde. 1. ed. Brasília, DF, 2009.

BRASIL. Resolução COFEN $n^{\circ}$ 427/2012. Normatiza os procedimentos da enfermagem no emprego de contenção mecânica de pacientes. Brasília/DF, 7 de maio de 2012.

FLORES, J. F. A; BETTINELLI, L. A; POMATTI, D. M. A equipe multiprofissional frente ao uso da contenção mecânica. Revista Contexto \& Saúde. V. 10, nº 20, jan.-jun. 2011.

GUIMARÂES, A. N; et al. Tratamento em saúde mental no modelo manicomial(1960 a 2000): histórias narradas por profissionais de enfermagem. Texto Contexto Enfermagem Florianópolis. v. 22, nº.2, pág.361-9, abr-jun.2013.

HUSM. Manual de Gerenciamento da Rotina - Unidade de Atenção Psicossocial (UAP). Agosto. 2016.

MARQUES, C. R. Contenção mecânica em pediatria: uma forma de violência institucional?. Universidade Federal do Rio Grande do Sul. Escola de Enfermagem. Trabalho de conclusão de curso. Porto Alegre. 2012.

MINAYO, M. C. S. O desafio da pesquisa social. Pesquisa social: Teoria, método e criatividade. 28 ed. Petrópolis, RJ. Vozes, 2009. 2014.

ROCHA, F. C. V. Procedimento Operacional Padrão. Hospital Getúlio Vargas.

SOUZA, L. M. S. Contenção mecânica no ambiente hospitalar: estudo transversal. 2018. 71 f. Dissertação (Mestrado Profissional Enfermagem Assistencial) - Universidade Federal Fluminense Escola de Enfermagem Aurora de Afonso Costa, Niterói, Rio de Janeiro. 2018. 